\title{
Editorial: Dating the Tree of Life
}

\author{
R. Alexander Pyron ${ }^{1 *}$ and Michel Laurin ${ }^{2}$ \\ ${ }^{1}$ Department of Biological Sciences, George Washington University, Washington DC, USA, ${ }^{2}$ CR2P (UMR 7207) Centre de \\ Recherche sur la Paléobiodiversité et les Paléoenvironnements (Centre National de la Recherche Scientifique /MNHN/UPMC, \\ Sorbonne Universités), Paris, France
}

Keywords: systematics, paleontology, molecular dating, evolution, phylogenetics

\section{Editorial on the Research Topic}

\section{Dating the Tree of Life}

The Tree of Life has an inherently temporal component, which was often overlooked in the early history of systematics. Every branch in a phylogeny has a specific beginning and end in time, and every node has an age. The last 30 years or so have seen an increasing sophistication and ubiquity of methods designed to estimate or infer these ages. These methods are based on diverse data sources such as direct observation of fossils, stratigraphic assignment of fossil ages from geological horizons, and rates of morphological and molecular change estimated from clock models. In light of the increasingly widespread adoption of these methods to understand the historical context of evolution, we commissioned several articles under the research topic "Dating the Tree of Life." These papers explore current perspectives and future prospects for the integration of morphological and molecular data for extinct and extant taxa in the context of a unified, dated phylogeny for the biodiversity of Earth.

Laurin summarized recent developments and areas for future research in dating methodologies for producing timetrees. One is the creation, curation, and maintenance of more sophisticated databases and matrices for paleontological data, including stratigraphic and morphological characters. Another is the calculation of more precise and accurate confidence intervals for geological age of origin of extinct species. A final area is the use of more sophisticated birth-death models to calculated inferred ages based on substitution rates.

Hipsley and Müller evaluated the empirical realities of fossil-calibration practices. These typically rely primarily on node ages calibrated by the occurrence of an extinct taxon hypothesized to constrain that node, but also include geological events and secondary calibrations to parameterize dates. They conclude, in part, that justifying fossil calibrations is of the utmost importance, and that unified best practices are needed to standardize divergence dating across studies and taxa to unify the dated Tree of Life.

Sharma and Giribet present an integrated fossil and molecular analysis of Opilione phylogeny, using sophisticated new tip-dating methods (Pyron, 2011) to incorporate paleontological data into molecular divergence-time estimation. They find strong support for diversification of Opiliones beginning in the Ordovician-Devonian periods. Their results highlight the importance that discovery of fossils of early taxa can have on inferred ages and relationships for diverse groups, and greater uncertainty on nodal ages in parts of the tree lacking temporal calibration constraints.

Caetano-Anollés et al. present an expansive view of the early Timetree of Life using phylogenomics (especially the history of protein domain structure) to assess early archaeal, bacterial, and eukaryotic lineages. They find a roughly $2.9 \mathrm{Ga}$ stem-age for the divergence and diversification of these groups. Their results provide an important early window on the functional evolution of molecular structure and protein function that drove the early history of life.

van Tuinen and Torres offer a cautionary perspective on the influence of uncertainty in estimated timetrees. When species radiate rapidly and speciation events are clustered in time, 
confidence intervals for estimated ages may overlap significantly and obscure diversification patterns. Saturation in variable nucleotide positions can also increase uncertainty. Surprisingly, the shallowest nodes seem to be the most difficult to date precisely, even when using multiple calibration constraints. These issues can be further compounded by the problems raised by Hipsley and Müller; if calibrations are poorly specified, this can have knock-on effects up and down the tree, skewing estimated node-ages across temporal scales.

Finally, Sanmartin and Meseguer offer a view of the downstream uses and impacts of dated phylogenies for understanding regional patterns of extinction and the longterm development of global patterns in biogeographic diversity. Extinction has subtle but profound impacts on the shape of phylogenetic trees, as well as correspondingly important influences on the development of regional biogeographic structure. The power available in contemporary datasets to detect these signatures is variable, but several promising approaches allow us to infer lineage extinction from trees, mass-extinction events, and local extinction of lineages. These, along with a greater integration of fossils into such analyses (Didier et al.,

\section{REFERENCES}

Didier, G., Fau, M., and Laurin, M. (2017). Likelihood of tree topologies with fossils and diversification rates estimation. Syst. Biol. doi: 10.1093/sysbio/syx045. [Epub ahead of print].

Pyron, R. A. (2011). Divergence-time estimation using fossils as terminal taxa and the origins of Lissamphibia. Syst. Biol. 60, 466-481. doi: 10.1093/sysbio/syr047

Conflict of Interest Statement: The authors declare that the research was conducted in the absence of any commercial or financial relationships that could be construed as a potential conflict of interest.
2017), combine to offer inferential historical perspectives on global biodiversity.

Together, these six articles represent a broad cross-section of the diversity of modern approaches to dating the tree of life. While there are a number of methodological cautions to be observed and numerous potential sources of error, timetrees offer crucial perspectives on the timing, tempo, and mode of diversification. These influence our understanding of everything from the early modification of protein function that led to the rise of eukaryotic biodiversity, to the development of regional biogeographic assemblages in response to recent climatic shifts. The future is wide-open for the further development and refinement of these approaches, and their application in systematics and evolutionary biology. Most importantly, these approaches offer great opportunities to productively improve the synergy between paleontology and molecular biology.

\section{AUTHOR CONTRIBUTIONS}

All authors listed, have made substantial, direct, and intellectual contribution to the work, and approved it for publication.
Copyright (c) 2017 Pyron and Laurin. This is an open-access article distributed under the terms of the Creative Commons Attribution License (CC BY). The use, distribution or reproduction in other forums is permitted, provided the original author(s) or licensor are credited and that the original publication in this journal is cited, in accordance with accepted academic practice. No use, distribution or reproduction is permitted which does not comply with these terms. 